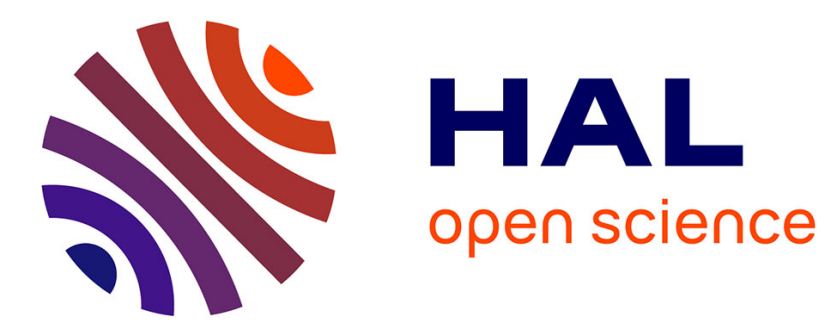

\title{
Observation of two longitudinal and two transverse waves in a frozen porous medium
}

Philippe Leclaire, Frédéric Cohen-Ténoudji, Jaime Aguirre-Puente

\section{To cite this version:}

Philippe Leclaire, Frédéric Cohen-Ténoudji, Jaime Aguirre-Puente. Observation of two longitudinal and two transverse waves in a frozen porous medium. Journal of the Acoustical Society of America, 1995, 97 (4), pp.2052. 10.1121/1.411997 . hal-01330318

\section{HAL Id: hal-01330318 https://hal.science/hal-01330318}

Submitted on 10 Jun 2016

HAL is a multi-disciplinary open access archive for the deposit and dissemination of scientific research documents, whether they are published or not. The documents may come from teaching and research institutions in France or abroad, or from public or private research centers.
L'archive ouverte pluridisciplinaire HAL, est destinée au dépôt et à la diffusion de documents scientifiques de niveau recherche, publiés ou non, émanant des établissements d'enseignement et de recherche français ou étrangers, des laboratoires publics ou privés. 


\title{
Observation of two longitudinal and two transverse waves in a frozen porous medium
}

\author{
P. Leclaire and F. Cohen-Ténoudji \\ L. U. A. P. Université D. Diderot (Paris 7), 2 place Jussieu, 75251 Paris Cedex 05, France \\ J. Aguirre-Puente \\ Centre de Gémorphologie du C.N.R.S., 24 avenue des tilleuls, 14000 Caen, France
}

\begin{abstract}
Experimental results on the transmission of elastic waves in a water-saturated sample of glass powder are presented. Both longitudinal and transverse waves are studied in a temperature range of $\left[-30,0^{\circ} \mathrm{C}\right]$. Two longitudinal and two transverse waves are detected. For a temperature of $-28{ }^{\circ} \mathrm{C}$ and a frequency of $500 \mathrm{kHz}$, the measured velocities are of the order of 4000 and $2300 \mathrm{~m} / \mathrm{s}$ for the two longitudinal waves and of 2400 and $1400 \mathrm{~m} / \mathrm{s}$ for the two transverse waves. The two supplementary signals detected (one longitudinal and one transverse) are very unlikely the result of spurious reflections or electromagnetic coupling since such phenomena were not observed when replacing the porous sample by water. The values of the experimental velocities are in good agreement with the predictions of the extension of Biot's theory to frozen porous media developed by Leclaire et al.
\end{abstract}

\section{INTRODUCTION}

The theory of propagation of elastic waves in fluidsaturated porous solids has been established by Biot in 1956 . Several authors have shown the validity of this theory (Berryman, 1980; Johnson and Plona, 1982) and its great interest for the interpretation of geophysical results (Murphy, 1982; Bourbié et al., 1987; Hovem and Ingram, 1979). A particular feature of Biot's theory is the prediction of two longitudinal waves in a consolidated medium as a consequence of the presence of solid and fluid in the porous medium: a fast wave and a second wave with a lower velocity. The viscous dissipations are responsible of a large attenuation of the second wave and make its detection difficult in almost all the experimental situations. In fact, the dispersion of the second wave also called Biot's slow wave can be assimilated to a diffusion process (Biot, 1956). The observation of the slow wave has been successfully performed by Plona and Johnson (1980) in a consolidated water-saturated sample of sintered glass beads.

An extension of Biot's theory to frozen porous media has been proposed recently by Leclaire et al. (1994) for applications in civil engineering and geophysics in cold regions. Let us recall that solid substrate, ice and liquid water can coexist in finely dispersed frozen media at negative Celsius temperatures and that water tends to form a film around the solid particles isolating them from ice (Aguirre-Puente and Bernard, 1978). The model of Leclaire et al. predicts that three longitudinal and two transverse acoustic waves can propagate in a three-phased material containing a solid substrate, ice, and liquid water. The purpose of this paper is to report investigations on the possible existence of several waves in frozen porous media and to give the interpretation of the experimental results with the help of the theoretical predictions.

\section{EXPERIMENTAL SETUP}

Laboratory tests have been performed in a nonconsolidated glass powder sample of porosity 0.3 and composed of mean size particles of about $120 \mu \mathrm{m}$. The experimental setup is shown in Fig. 1. A cell made of Plexiglas containing the water-saturated sample at ambient temperature is dropped to $-30^{\circ} \mathrm{C}$. During a slow reheating over $10 \mathrm{~h}$ in an isolating enclosure, temperature is monitored by thermocouples located in the sample while acoustical measurements are made. They consist in the transmission through the sample of short acoustical pulses ( $-300-\mathrm{V}$ amplitude, $1-\mu$ s duration) generated by a pulse generator. The selection of the longitudinal or transverse mode is made by switches in emission and reception. The transducers nominal frequency is $500 \mathrm{kHz}$. The signals are amplified and displayed on a sampling oscilloscope triggered by the pulse generator. Then the signals are digitized with a 12-bit A/D converter and recorded by a microcomputer for analysis in time or frequency domain.

Our first experiments (Leclaire et al., 1993) were designed to determine the velocity and attenuation for samples at temperatures in the vicinity of $0{ }^{\circ} \mathrm{C}$. For these experiments the propagation distance in the sample was around $2 \mathrm{~cm}$ to reduce amplitude decay when the medium is almost totally defrosted. In such a configuration, wave reflections occur at sample/cell and transducers/cell interfaces. The reflections appear on the oscilloscope as spurious oscillations at the end of the signals and prevent the detection of possible other waves. A new cell has been made (Fig. 2) with perforated walls at the transducers diameter to eliminate reflections in the cell. Transducers are applied directly on the sample. The propagation distance is increased up to $9.7 \mathrm{~cm}$ to isolate 


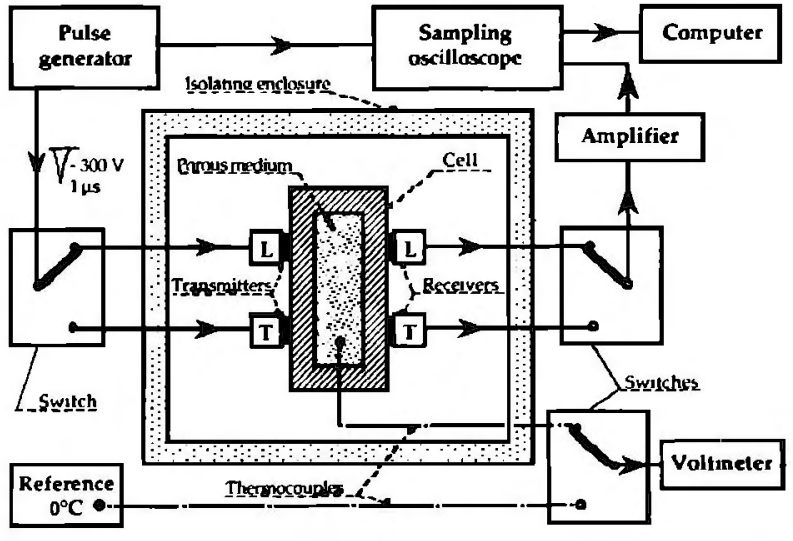

FIG. 1. Experimental setup for the study of acoustic waves in frozen porous media. The cell is rectangularly shaped and the sample thickness is $2 \mathrm{~cm}$.

useful signals from unexpected reflections and to improve the precision of the velocity measurement. Although the propagation distance is increased, signal should be observed at low temperatures where wave attenuation is low. No vacuum was used during the preparation of the sample as we assume that the influence of air bubbles on velocities is small at low temperature.

\section{RESULTS}

Figure 3 shows the signal received by longitudinal [Fig. 3(a)] and transverse [Fig. 3(b)] transducer for a temperature of $-28^{\circ} \mathrm{C}$. We observe two signals for each mode which have been marked $\Lambda 1, \Lambda 2$ for longitudinal modes and $\theta 1, \theta 2$ for transverse modes. As seen in Fig. 4 for a temperature of $-11.5^{\circ} \mathrm{C}$, the arrival time of the signals increases with temperature as the medium defreezes, their amplitude decreases and they lose their high-frequency content. These remarks apply noticeably more for transverse waves. The evolution of the amplitude and of the delay of the signals between -5 and $-2{ }^{\circ} \mathrm{C}$ is shown in Fig. 5. One may observe a large increase of the delay of $\theta 1$ between these temperatures while the variation of the delay of $\Lambda 2$ is smaller. The $\Lambda 1$ and $\theta 1$ waves have been studied in previous works (Leclaire et al., 1993). The previous results on velocity given by the ratio of the propagation distance to the delay of the received signal are comparable to those obtained in the present study but these last results may be considered as better since the measurements are morc accurate in the configuration of the cell of

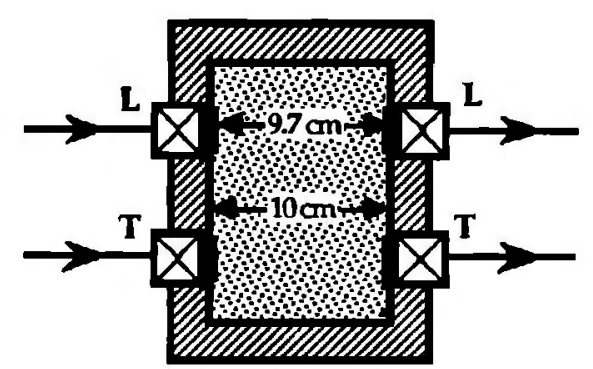

FIG. 2. New configuration of the rectangular cell containing the sample for the detection of possible secondary waves in frozen porous media. The propagation distance is now of $9.7 \mathrm{~cm}$ and the transducers are in direct contact with the sample.

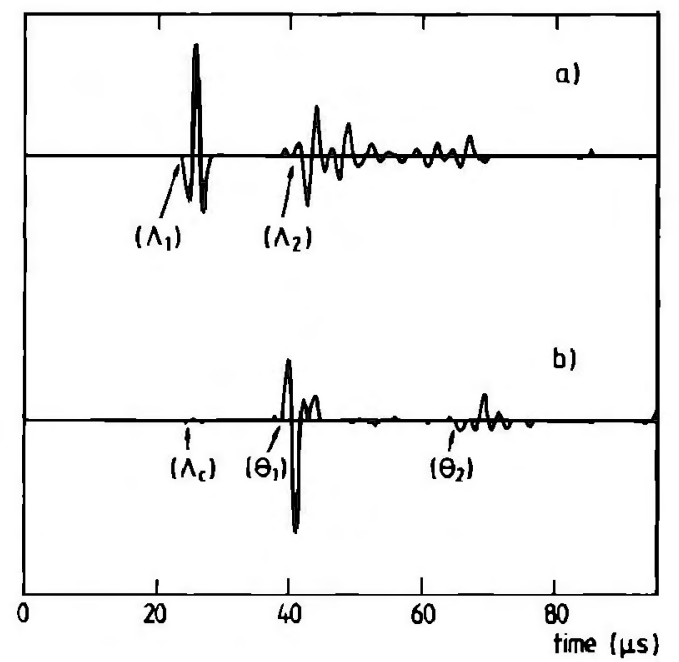

FIG. 3. Signals received by (a) longitudinal receiver and (b) transverse receiver at $-28{ }^{\circ} \mathrm{C}$ in glass powder.

Fig. 2, where the propagation distance is increased. On the other hand, wave attenuation is higher near $0{ }^{\circ} \mathrm{C}$ in this configuration. The time delay of the detected supplementary signals $\Lambda 2$ and $\theta 2$ is approximately twice as long as the delay of $\Lambda \mathrm{l}$ and $\theta \mathrm{l}$, respectively. Experiments have been made replacing the porous sample by water at room temperature to determine if these extra signals could be the result of spurious reflections on the cell walls or on the transducers surface. No signal was detected by the receiver at a time delay double of that of the first received signal. Thus $\Lambda 2$ and $\theta 2$ cannot be the consequence of wave reflections or electromagnetic coupling between the emission and the reception of the electronic apparatus. Considering transverse signals [Figs. 3(b) and 4(b)], one may observe a very small signal located by the marker $\Lambda c$ which correspond to a longitudinal component. Consequently, it is unlikely that $\theta 2$ can be a longitudinal component resulting from a mode conversion at the surface of the transverse transmitter since the amplitude of $\theta 2$ is much greater than the amplitude of $\Lambda \mathrm{c}$. Elsewhere, Fig. 5 shows that $\Lambda 2$ cannot be a longitudinal component resulting

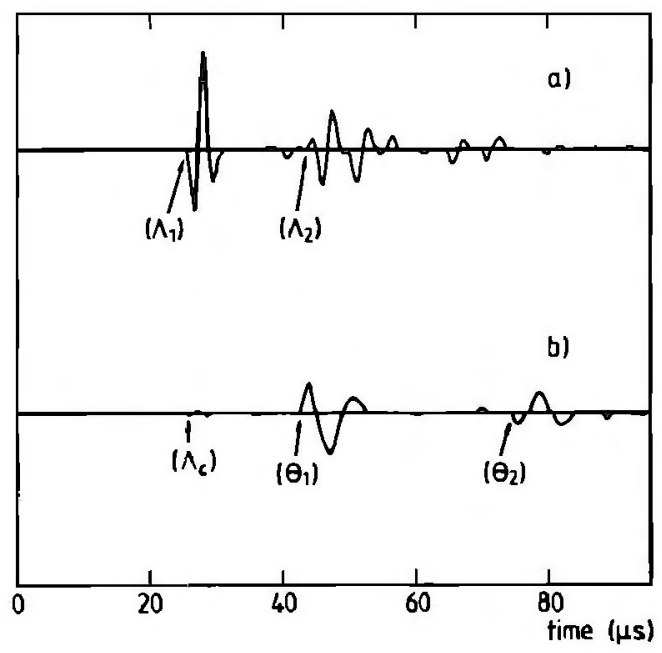

FIG. 4. Signals received by (a) longitudinal receiver and (b) transverse receiver at $-115^{\circ} \mathrm{C}$ in glass powder. 

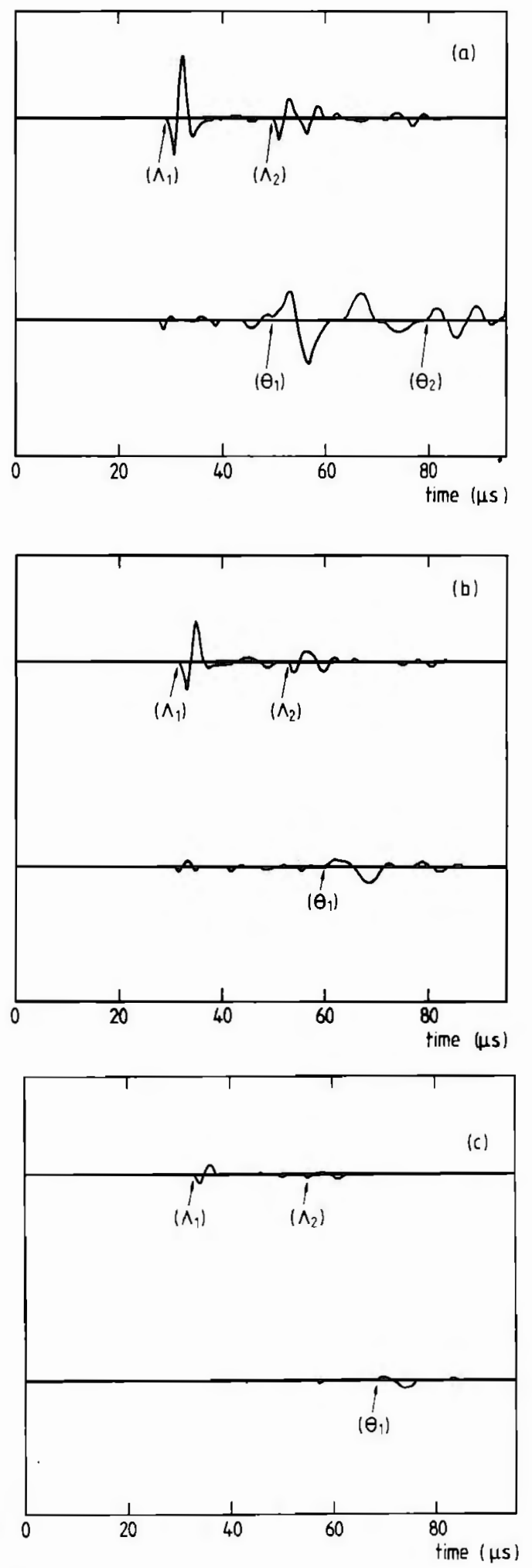

FIG. 5. Evolution of the signals between -5 and $-2{ }^{\circ} \mathrm{C}$. (a) signals at $-5{ }^{\circ} \mathrm{C}$, (b) signals at $-2.5^{\circ} \mathrm{C}$, and (c) signals at $-2{ }^{\circ} \mathrm{C}$.

from $\theta 1$ since a separation of the two signals occurs between -5 and $-2{ }^{\circ} \mathrm{C}$. In fact, $\Lambda 2$ and $\theta 2$ might be considered as secondary waves in frozen porous media. The relative shifts of signals $\Lambda 1, \Lambda 2, \theta 1$, and $\theta 2$ caused by temperature variations during the reheating have been followed by plotting their velocities as shown in Fig. 6.

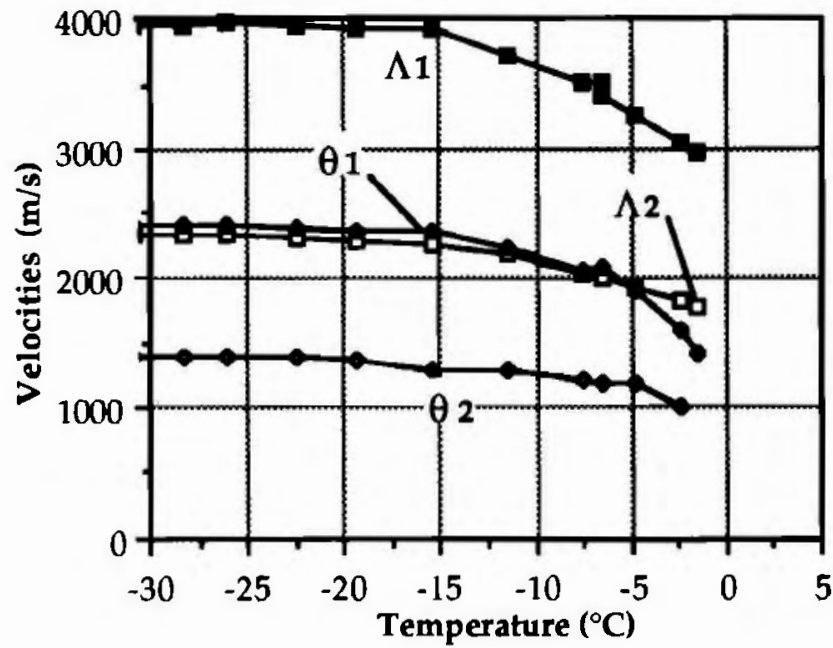

FIG. 6. Experimental velocities of $\Lambda 1, \Lambda 2, \theta 1$, and $\theta 2$ waves as functions of temperature (in glass powder).

\section{DISCUSSION}

The extension of Biot's theory to frozen porous media proposed by Leclaire et al. (1994) predicts the existence of three longitudinal waves labeled L1, L2, L3 and of two transverse waves labeled $\mathrm{T} 1, \mathrm{~T} 2$ whose velocity and attenuation can be expressed as functions of unfrozen water content. The velocity and attenuation can also be expressed as functions of temperature with the help of a thermodynamical relationship developed independently from the acoustic model, where physical parameters and porosimetric distribution play a role. Figure 7 shows the velocity of L1, L2, T1, and $\mathrm{T} 2$ waves calculated for glass powder with the theoretical model as functions of temperature and for a frequency of $500 \mathrm{kHz}$. For the calculation, porosimetric distribution has been assumed to be Gaussian with an average pore radius $r_{\text {ay }}$ of $10 \mu \mathrm{m}$ and a standard deviation $\Delta r$ of $4 \mu \mathrm{m}$. The large values of $r_{\mathrm{av}}$ and $\Delta r$ imply that large velocity variations exist between -1 and $0{ }^{\circ} \mathrm{C}$.

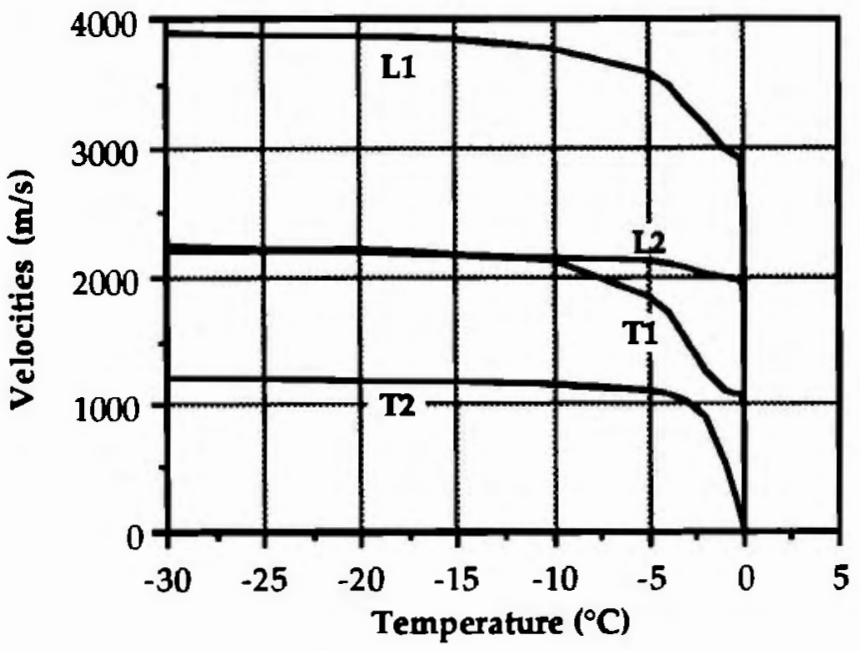

FIG. 7. Calculated velocities of $\Lambda 1, \Lambda 2, \theta 1$, and $\theta 2$ waves as functions of temperature at $500 \mathrm{kHz}$ (glass powder). 
The experimental velocities of $\Lambda 1$ and $\theta 1$ waves (Fig. 6) are in good agreement with the theoretical velocities of L1 and $\mathrm{T} 1$ waves (Fig. 7) in the range of temperature explored. In fact, one may identify the experimental longitudinal $\Lambda 1$ wave as the theoretical $\mathrm{L} 1$ wave, and the experimental transverse $\theta 1$ wave as the theoretical $\mathrm{T} 1$ wave. In the same way, the $\Lambda 2$ and $\theta 2$ waves might be identified as the L2 and as the $\mathrm{T} 2$ wave, respectively. This seems to be confirmed considering the good agreement obtained from the comparison of the experimental results (Fig. 6) to the theoretical predictions (Fig. 7).

The existence of two longitudinal waves in a watersaturated porous medium (without ice) is a consequence of the presence of two continuous phases in the medium but the two waves do not propagate independently, one wave in each phase. In fact, elastic and inertial coupling between water and solid imply exchanges of potential and kinetic energy (respectively) between the two waves. When dealing with frozen porous media, one could admit the possible existence of several waves if the phases are continuous as it can occur for porous media with ice. Elastic and inertial coupling can also occur between solid and liquid water and between ice and liquid water and could therefore influence the propagation. The theoretical model of Leclaire et al. (1994) predicts one longitudinal and one transverse wave in addition of those predicted by Biot's original theory. This is a consequence of the presence of one supplementary continuous solid (ice) in the medium. In a mathematical view, the prediction of several waves is a consequence of the use of Biot's formulation.

Although elastic and inertial coupling exist, we think that the main part of the energy of $\Lambda 1$ and $\theta 1$ propagates in the solid while symmetrically, the energy of $\Lambda 2$ and $\theta 2$ propagates mainly in the ice. The properties of $\Lambda 2$ and $\theta 2$ can therefore be considered as similar to those of $\Lambda 1$ and $\theta 1$. Biot's slow wave detected by Plona and Johnson (1980) is highly attenuated and behave as a diffusion process in the low-frequency range (Biot, 1956). Thus the $\Lambda 2$ and $\theta 2$ waves detected here are not assimilated as waves of this kind since they propagate with a low attenuation (with respect to Biot's slow wave) at low temperatures when the medium is almost totally frozen.

\section{CONCLUSION}

The extension of Biot's theory of wave propagation to frozen media has led to the prediction of three longitudinal and two transverse waves. Experiments have been made to detect possible supplementary waves in a nonconsolidated sample of glass powder. Supplementary signals other than those expected have been observed and might be associated to the existence of secondary waves. A good agreement has been found for the velocities between the experimental results and the theoretical predictions.

The results presented here seems to show that several longitudinal and transverse waves may propagate in porous media composed of continuous solids. The experimental and theoretical investigations in this direction should be of interest for applications in physics of heterogeneous materials.

Aguirre-Puente, J., and Bernard, J. J. (1978). Comportement au gel des matériatx de construction (Le comportement thermique des materiaux de construction), Editions du batiment et des travaux publics, pp. 29-72.

Berryman, J. G. (1980). "Confirmation of Biot's theory," Appl. Phys. Lett. 37(4), 382-384.

Biot, M. A. (1956). "Theory of propagation of elastic waves in a fluid saturated porous solid. Part I-Low frequency range," J. Acoust. Soc. Am. $28,168-178$.

Bourbié, T., Coussy, O, and Zinzner, B. (1987). Acoustics of Porous Media (Gulf Publishing, Houston).

Hovem, J. M., and Ingram, G. D. (1979). "Viscous attenuation of sound in saturated sands," J. Acoust. Soc. Am. 66, 1807-I8I2.

Johnson, D. L., and Plona, T. J. (1982). "Acoustic slow wave and the consolidation transition," J. Acoust. Soc. Am. 72, 556-565.

Leclaire, Ph., Cohen-Ténoudji, F., and Aguirre-Puente, J. (1993). "A Model of elastic wave propagation in frozen media. Comparison with experiments," Proc. VIth Int. Conf. on Permafrost, Beijing, China.

Leclaire, Ph., Cohen-T'énoudji, F., and Aguirre-Puente, J. (1994). "Extension of Biot's theory of wave propagation to frozen porous media." J. Acoust. Soc. Am. 96, 3753-3768.

Murphy, W. F., III (1982). "Effect of partial water saturation on attenuation in Massilon sandstone and Vycor porous glass," J. Acoust. Soc. Am. 71, 1458-1468.

Plona, T. J., and Johnson, D. L. (1980). "Experimental study of the two compressional modes in water-saturated porous structures," Proc. IEEE Ultrason. Symp. 868-871. 